\title{
Hypocritical organizations: Implications for employee social responsibility
}

\author{
Abstract \\ The implications of corporate hypocrisy for corporate social responsibility (CSR) at the \\ employee level of analysis remain largely unexplored. Drawing on attribution theory and the \\ sensemaking perspective of CSR, we develop a model that highlights the negative effects of \\ corporate hypocrisy on employees' voluntary contribution to their firm's social responsibility \\ programs (employee social responsibility, or ESR), as mediated by symbolic CSR \\ attributions. Moreover, by incorporating the CSR sensitivity framework, we develop a more \\ nuanced model that acknowledges the role of task significance in strengthening the \\ aforementioned relationship. The results from our cross-lagged study first suggest that \\ corporate hypocrisy negatively affects ESR through the intermediary role of symbolic CSR \\ attributions. Second, the findings reveal that task significance moderates the relationship \\ between corporate hypocrisy and ESR, such that both the direct and indirect effects are \\ stronger for employees whose jobs are higher in task significance. Implications for research \\ and practice are discussed.
}

Keywords: Attribution theory; Corporate hypocrisy; Employee social responsibility; Sensemaking; Symbolic CSR; Task significance 


\section{Hypocritical organizations: Implications for employee social responsibility}

\section{Introduction}

Growing stakeholder demands push organizations to increasingly portray themselves as complying with social and moral expectations, at the risk of being perceived as hypocritical when such commitments are not upheld (Carlos \& Lewis, 2018; Christensen, Morsing, \& Thyssen, 2013; Lyon \& Montgomery, 2013). Corporate hypocrisy, conceptualized as a lack of integrity, is a negative social evaluation that results from the perception of a distance between an organization's claimed standards and actions (i.e., word-deed misalignment Greenbaum, Mawritz, \& Piccolo, 2015; Wagner, Lutz, \& Weitz, 2009). For example, corporate hypocrisy may arise when an organization sends a message of valuing its employees and is later proved to have poor working conditions.

Research shows that corporate hypocrisy is especially salient and sparks strong negative reactions when stakeholders observe organizational word-deed misalignment in socially valued practices, such as unsubstantiated claims about product quality, employee health and safety, or environmental protection (Fassin \& Buelens, 2011; Shim \& Yang, 2016). Unsurprisingly, the study of stakeholder reactions to corporate hypocrisy has thus particularly flourished in the area of corporate social responsibility (CSR), or an organization's discretionary actions that contribute to the creation of social good (McWilliams, Siegel, \& Wright, 2006). Current research in this field indicates that corporate hypocrisy can result in stakeholder cynicism about and negative reactions to an organization's prosocial actions, including consumers' negative CSR beliefs and ire (Arli, Grace, Palmer, \& Pham, 2017; Marín, Cuestas, \& Román, 2016; Wagner et al., 2009), distrust and skepticism toward environmental claims (Chen \& Chang, 2013), negative word of mouth, and lower purchase intentions (Leonidou \& Skarmeas, 2017), as well as stock market sanctions (Bansal \& Clelland, 2004; Janney \& Gove, 2011) and accusations of social irresponsibility by media, 
activists, and citizens (Lyon \& Montgomery, 2013; Zavyalova, Pfarrer, Reger, \& Shapiro, 2012).

Despite such findings, the literature to date remains largely silent on internal stakeholders' (i.e., employees') reactions to corporate hypocrisy (for a notable exception, see Scheidler, Edinger-Schons, Spanjol, \& Wieseke, 2019). Indeed, the lack of employee-level focus in this research area is surprising given that internal stakeholders can more readily attend to their organization's various actions and thus identify word-deed misalignments better than external stakeholders (e.g., consumers, investors), who are somewhat limited in their ability to detect corporate hypocrisy (Carlos \& Lewis, 2018; Ramus \& Montiel, 2005; Scheidler et al., 2019). Moreover, with regard to CSR, widespread employee participation in social responsibility initiatives is a critical factor signaling to external stakeholders that the organization is "walking the talk" (Aguinis \& Glavas, 2019; De Roeck \& Farooq, 2018). As such, the study of employees' responses to organizational word-deed misalignments, notably in terms of CSR engagement, also has implications for other stakeholders' perceptions of and reactions to corporate hypocrisy (Fassin \& Buelens, 2011).

Accordingly, this paper aims to shift the focus of the current corporate hypocrisy literature to internal stakeholders by addressing the following research question: how might corporate hypocrisy affect employees' beliefs and engagement in their organization's CSR initiatives? We conceptualize this engagement as employee social responsibility (ESR), or extra-role behaviors that contribute to an organization's CSR programs ${ }^{1}$ (De Roeck \& Farooq, 2018; Vlachos, Panagopoulos, \& Rapp, 2014), such as getting involved in the

\footnotetext{
${ }^{1}$ ESR bears similarities to organizational citizenship behaviors, or employee extra-role behaviors that promote the effective functioning of the organization (Organ, 1988); however, a key distinction is that ESR focuses on discretionary behaviors targeting positive societal change (De Roeck \& Farooq, 2018; Gond, El Akremi, Swaen, \& Babu, 2017).
} 
implementation of such CSR programs (e.g., volunteering), or taking initiative to improve existing CSR practices (e.g., suggesting changes to waste management procedures).

To address our research question, we first draw on attribution theory (Kelley \& Michela, 1980) and the sensemaking perspective of CSR (Aguinis \& Glavas, 2019). Here, we suggest that corporate hypocrisy informs employee sensemaking processes around CSR, consequently influencing the development of their CSR attributions (i.e., individual beliefs about their organization's underlying motives for engaging in CSR) (Donia, Tetrault Sirsly, \& Ronen, 2017b; Vlachos, Theotokis, \& Panagopoulos, 2010), which serve to mediate the negative effects of corporate hypocrisy on ESR. Moreover, drawing on the CSR sensitivity framework (Ong, Mayer, Tost, \& Wellman, 2018), we hypothesize that task significance, or the degree to which an employee views their job as positively influencing the lives and/or work of others (Hackman \& Oldham, 1975), represents a central aspect of personal work experiences that can strengthen his or her negative reactions to corporate hypocrisy.

This study makes three key contributions. First, it introduces a micro-level approach to the study of corporate hypocrisy by investigating its implications for employee behavior, and in particular ESR. In doing so, we also contribute to the micro-CSR literature, which has issued repeated calls to bring greater focus to organizational factors influencing employee engagement with CSR in the workplace, including those that may result in employee disengagement from or even sabotage of an organization's CSR efforts (De Roeck \& Maon, 2018; Gond et al., 2017; Hejjas, Miller, \& Scarles, 2019; Paillé, Morelos, Raineri, \& Stinglhamber, 2019; Rodrigo \& Arenas, 2008; Rupp \& Mallory, 2015). Second, we draw on attribution theory to explain how symbolic CSR attributions, in which the organization is judged as engaging in CSR to opportunistically reap reputational and financial benefits (Donia, Ronen, Tetrault Sirsly, \& Bonaccio, 2017a), play a key role in mediating the negative effects of corporate hypocrisy on ESR. As such, we address calls to explore the factors that 
influence employees' sensemaking processes around CSR (Aguinis \& Glavas, 2019) and also advance the scarce research investigating the predictors of employees' CSR attributions (Donia et al., 2017a; Gond et al., 2017; Vlachos, Panagopoulos, Bachrach, \& Morgeson, 2017). Third, we provide support for Ong et al.’s (2018) CSR sensitivity framework by suggesting that task significance interacts with corporate hypocrisy to influence ESR, thereby extending work on the boundary conditions determining employees' discretionary engagement in socially responsible behaviors (e.g., De Roeck \& Farooq, 2018).

\section{Background: Attribution theory and the sensemaking perspective of CSR}

To explain why and how employees react negatively to corporate hypocrisy, we draw on attribution theory and the sensemaking perspective (Kelley \& Michela, 1980; Weick, 1995), which suggest that individuals strive to understand and make sense of the motivations underlying the actions of social actors (whether individual or collective), to better adapt their behavior to their social environment (Lange \& Washburn, 2012). Specifically, when judging a certain action, individuals take cues not only from the action itself but also from their prior knowledge or beliefs about a social actor. That is, individuals' salient pre-existing views of others (e.g., judgments of hypocrisy) may act as a heuristic (i.e., exert a halo effect) that bears on and skews their attributional processes (Godfrey, 2005; Lange \& Washburn, 2012).

Therefore, when judging the credibility of a claim or the motive underlying an organization's action, individuals will draw on their previous knowledge of similar situations and interpret the focal behavior in terms of the general pattern of conduct of the organization (Carlos \& Lewis 2018; Leonidou \& Skarmeas, 2017). For example, Burberry, which has established its identity as a luxury brand with a unique British heritage and has marketed itself on its British appeal, was accused of being hypocritical when it closed down its British factories and moved hundreds of jobs to China (Cadwalladr, 2012). Arguably, both internal and external stakeholders might perceive the organization as being hypocritical and go on to view its 
future actions through this hypocrisy-tinted lens. Indeed, prior research shows that organizations whose words are inconsistent with their deeds (i.e., hypocritical) are marred by a lack of credibility (e.g., Chen \& Chang, 2013; Mazutis \& Slawinski, 2015; Zavyalova et al., 2012), which may lead individuals to view all organizational actions with skepticism (Carlos \& Lewis, 2018), especially those that are prosocial in nature (Leonidou \& Skarmeas, 2017; Lyon \& Montgomery, 2013).

Accordingly, this rationale is consistent with the sensemaking perspective of CSR (Aguinis \& Glavas, 2019), which argues that in their search for meaningfulness through work, employees actively scan their work environment for clues that might indicate the motives underlying their organization's prosocial actions. More specifically, together with attribution theory, this perspective suggests that corporate hypocrisy might serve as a salient cue that influences how individuals make sense of an organization's actions by triggering their suspicion about its motives for engaging in CSR practices (e.g., Bae \& Cameron, 2006; Chen \& Chang, 2013; Marín et al., 2016; Shim \& Yang, 2016). For example, because of fastfood giant McDonald's past lies regarding its claims about food safety, labor standards, and animal treatment (i.e., salient pre-existing views of the organization's lack of integrity), stakeholders remained highly skeptical about its CSR initiatives launched in 2012 centered on supporting economically viable farming through the protection of land, livestock, and livelihoods, which eventually resulted in a media disaster (Lyon \& Montgomery, 2013).

In line with this example, research suggests that perceptions of word-deed misalignments are negatively related to stakeholders' judgements of organizational trust (Chen \& Chang, 2013), credibility (Carlos \& Lewis, 2018), and authenticity (Mazutis \& Slawinski, 2015); and that stakeholders might thus suspect self-serving motivations behind CSR practices (Marín et al., 2016; Shim \& Yang, 2016; Zavyalova et al., 2012). For instance, Arli et al. (2017) demonstrate the negative effects of corporate hypocrisy on consumer attitudes toward the 
firm indirectly through its effects on CSR beliefs and corporate reputation. Likewise, Wagner et al. (2009) highlight the ill effects of corporate hypocrisy on negative consumer CSR beliefs and attitudes toward the organization, whereas Marín et al. (2016) demonstrate that when consumers perceive hypocrisy, they attribute egoistic motives to the organization's CSR practices. Given these insights, we propose that corporate hypocrisy negatively affects employees' CSR attributions and, as a result, their discretionary engagement in the company's CSR programs. We provide a more detailed rationale supporting this proposition as well as the conditions under which such a phenomenon is more likely to occur subsequently.

\section{Hypotheses development}

\subsection{Corporate hypocrisy, symbolic CSR attributions, and ESR}

Drawing on both attribution theory and the sensemaking perspective of CSR, we suggest that employees rely on their perceptions of corporate hypocrisy to make sense of the motives underlying their organization's CSR activities (i.e., CSR attributions), which in turn affect their discretionary engagement in socially responsible behavior (i.e., ESR). In general, stakeholders' attributions of an organization's CSR motives may be of two kinds (Du, Bhattacharya, \& Sen, 2010; Skarmeas \& Leonidou, 2013): substantive (or genuine), in which stakeholders perceive the organization as acting out of a sincere desire to contribute to social good, or symbolic (self-serving), in which stakeholders perceive the organization as attempting to reap reputational and financial benefits through its CSR initiatives (e.g., Donia et al., 2017a, 2017b; Vlachos et al., 2017). Therefore, relying on the rationale developed in our theoretical discussion, we argue that corporate hypocrisy may act as a heuristic (i.e., exert a halo effect) that skews employees' attributional processes, leading them to attribute more symbolic motives to their organization's CSR. 
Furthermore, we identify symbolic CSR attributions as a key mediator in the relationship between corporate hypocrisy and ESR. Indeed, attribution theory holds that "people interpret behavior in terms of its causes and that these interpretations play an important role in determining their reactions to the behavior" (Kelley \& Michela, 1980, p. 458). CSR research grounded in both attribution theory and the sensemaking perspective tends to indicate that when employees consider CSR to be substantive, they are more likely to get involved in CSR as a way to find more meaningfulness through work (Aguinis \& Glavas, 2019, Donia et al., 2017a). Conversely, when CSR is deemed symbolic, employees are less likely to engage in ESR because they believe that cause-exploitative CSR (vs. CSR rooted in a sincere desire to benefit others) will provide little meaningfulness to their work. In support of this contention, empirical evidence shows that employees' symbolic CSR attributions negatively affect both employee work meaningfulness and extra-role behavior (e.g., Donia et al., 2017b; Vlachos et al., 2010, 2014). Similarly, Hejjas et al.'s (2019) qualitative study shows that employees' skepticism about the sincerity and effectiveness of their organization's CSR practices is a primary cause of ESR disengagement. Therefore, consistent with the reviewed arguments and empirical findings, we propose that employees form symbolic CSR attributions in response to corporate hypocrisy, leading to disengagement from socially responsible behavior. Thus:

H1: Symbolic CSR attributions mediate the negative effects of corporate hypocrisy on ESR.

\subsection{The moderating role of task significance}

In a recent study, Ong et al. (2018) suggest that employees can differ in their level of CSR sensitivity, or "the extent to which employees are behaviorally influenced by their organizations' CSR activities" (p. 45), depending on the task significance element of their job (i.e., the degree to which employees perceive their job as having a positive impact on others). Indeed, prior research indicates that task significance contributes to activating and increasing 
employees' desire to have a positive and genuine social impact, thereby making them more sensitive to the environment surrounding their prosocial actions (Grant, 2008), and those of their organization (Ong et al., 2018). As such, task significance is a key factor that can heighten employees' sensitivity to contextual cues, such as corporate hypocrisy, that may tarnish their organization's CSR activities, and consequently their own social responsibility efforts. Thus, the higher the task significance, the more employees should give importance to the organization's integrity, and the perceived alignment between its words and deeds. This enhanced sensitivity resulting from task significance should therefore increase the likelihood that they will more strongly react to corporate hypocrisy, given that corporate hypocrisy will reduce the meaningfulness and impact of their own involvement in ESR.

In summary, we argue that corporate hypocrisy causes employees with higher levels of task significance to more strongly disengage from ESR, as these employees perceive their potential ESR efforts as having little chance of making a substantial impact on the lives of others. By contrast, employees with lower task significance have a reduced sensitivity to the creation of social good through their work, and as a consequence, the negative implications of corporate hypocrisy for ESR should be weaker. Thus:

H2: Task significance moderates the negative effects of corporate hypocrisy on ESR, such that the relationship is more negative when task significance is high.

Following $\mathrm{H} 1$ and $\mathrm{H} 2$, we further propose:

H3: Task significance moderates the indirect negative effects of corporate hypocrisy on ESR through symbolic CSR attributions, such that the indirect relationship is more negative when task significance is higher.

\section{Methods}

\subsection{Procedure and sample}


To obtain a diverse sample of job types and organizations, we acquired the names and email addresses of a random sample of 2,500 alumni who graduated from a French Business School between 1991 and 2016. Respondents were asked to complete two confidential online questionnaires with a three-month interval in between. We measured corporate hypocrisy, symbolic CSR attributions, and task significance at time 1 and ESR three months later at time 2.

In total, 733 individuals (29.3\% response rate) responded at time 1. After filtering out unusable returns with a person-level response rate below 30\% (Newman, 2014), including people who were not employed at the time of the study, we were left with 457 completed questionnaires for analysis at time 1 . The time 2 questionnaire was completed three months later by 193 individuals (42.2\% response rate). We excluded 11 respondents from the analysis because they changed organizations or jobs between time 1 and time 2, as well as 27 respondents who declared having no awareness/knowledge of their organization's CSR initiatives, leaving a total sample of 155 employees. Table 1 shows the characteristics of the sample.

\section{Insert Table 1 here}

\subsection{Measures}

We translated the questionnaire items into French through a standard translation-backtranslation procedure. All variables were rated on a 5-point Likert scale, anchored by strongly disagree (1) and strongly agree (5). We retained all items used in the questionnaire to measure the constructs under study for analysis (for a detailed overview of the items and construct validity, see the Appendix).

We measured corporate hypocrisy using the six-item scale of Wagner et al. (2009). This scale assesses the extent to which employees believe there is a gap between what their 
organization claims and what their organization actually does. Three of these items were reverse scored, with higher scores indicating stronger corporate hypocrisy beliefs. Sample items include "What my organization says and does are two different things" and "My organization keeps its promises" (reverse-scored item). Cronbach's alpha for this measure was 0.93 .

We measured symbolic CSR attributions with four items developed by Donia et al. (2017b). The items assess the extent to which employees judge CSR initiatives as being instrumental and driven by a desire to benefit the organization itself. A sample item includes "My organization engages in CSR initiatives to look better than its competitors." Cronbach's alpha was 0.86 .

We measured task significance with the three items from the Job Diagnostic Survey (Hackman \& Oldham, 1975), as revised by Morgeson and Humphrey (2006). This scale assesses the degree to which the job influences the lives or work of others. A sample item is "The results of my work are likely to significantly affect the lives of other people." Cronbach's alpha was 0.86 .

For employee social responsibility (ESR), we used the three-item scale of Vlachos et al. (2014), which measures extra-role CSR-specific performance. The scale items assess engagement in voluntary behaviors that support the organization's achievement of its CSR goals. A sample item is "Over the past three months I got actively involved in the implementation of my organization's CSR initiatives.” Cronbach's alpha was 0.85 .

Following Ong et al. (2018), we controlled for demographic variables, given that they can affect the core constructs and relationships in our study. Specifically, we controlled for gender because it can account for variance in ESR (e.g., De Roeck \& Farooq, 2018). Age served as a control variable because older people tend to be more prosocial than younger people (Donia et al., 2017a). We also controlled for organization tenure and job level because 
length of time spent in an organization and the amount of power one has at work are both linked to prosociality (Ong et al., 2018). Last, we included job satisfaction as a control variable at time 1 using a single-item measure ("Overall, I am very satisfied with my job"; 1 $=$ very strongly disagree, $7=$ very strongly agree $)$, because job satisfaction is an important construct that can influence employee attributions and prosocial behavior (Donia et al., 2017a).

\subsection{Measurement validation}

We conducted confirmatory factor analyses using Mplus (Muthén \& Muthén, 2013) to assess the fit of our data to the measurement model and the distinctiveness of the four constructs: corporate hypocrisy, symbolic CSR attributions, task significance, and ESR. We established the goodness of fit using the maximum likelihood-based comparative fit index (CFI), Tucker-Lewis index (TLI), and root mean square error of approximation (RMSEA). Cutoff values greater than or equal to 0.95 for CFI and TLI and lower than or equal to 0.06 for RMSEA are indicative of good fit between the research model and the observed data $\mathrm{Hu}$ \& Bentler, 1999).

As Table 2 depicts, our theoretical measurement model including four factors yielded a good fit to the data $\left(\chi^{2}=151.72, d f=97, p<.001 ; \mathrm{CFI}=0.96 ; \mathrm{TLI}=0.95 ; \mathrm{RMSEA}=0.06\right)$. Then, using chi-square difference tests (Bentler \& Bonett, 1980), we compared the fit of our theoretical model with a sequence of four nested models representing simpler representations of the data. The results in Table 2 show that our theoretical four-factor model produced a superior fit to the data over the alternative models. Furthermore, the hypothesized factor loadings were all statistically significant; Table 3 shows that the Jöreskog's rho index of composite reliability $(\rho)$ and the average variance extracted $\left(\rho_{v c(\eta)}\right)$ values of the constructs were above the 0.70 and 0.50 threshold values, respectively (Fornell \& Larcker, 1981; Hair, 
Black, Babin, \& Anderson, 2010). These findings support the hypothesized model and indicate convergent and discriminant validity of our variables.

Insert Tables 2 and 3 here

\subsection{Common Method Variance}

Although we used a cross-lagged design with two measurement time points, we collected data from single sources on self-report measures, which may be a source of common method variance (CMV). Therefore, we partitioned the total variance among trait, method, and uniqueness using the single unmeasured latent method factor technique, so as to verify that systematic error variance did not account for the observed relationships between the constructs (Podsakoff, MacKenzie, Lee, \& Podsakoff, 2003). The results indicated no improvement in fit indices $\left(\chi^{2}=151.72, d f=96, p<.001 ; \mathrm{CFI}=0.96\right.$; TLI $=0.95 ; \mathrm{RMSEA}=$ 0.06), and none of the method factor loadings were significant $(p>.05)$, suggesting that common method bias was not a significant problem in our data.

\section{Results}

Table 3 provides the descriptive statistics, including means, standard deviations, and intercorrelations among the variables used to test the hypotheses. Following Becker, Atinc, Breaugh, Carlson, Edwards, and Spector (2016), we excluded gender and organizational tenure from subsequent analyses because these control variables did not correlate significantly with the other study variables.

Because our hypotheses involved indirect (H1), conditional (H2), and conditional indirect (H3) effects, we tested our research model using the Hayes (2013) PROCESS macro. This macro tests (moderated) mediation according to a bootstrap method: a nonparametric resampling procedure "that does not impose the assumption of normality of the sampling distribution" (Preacher \& Hayes, 2008, p. 880). For the bootstrap analyses, we used bias- 
corrected estimates from 5,000 random replicates with replacement from the full sample (Cheung \& Lau, 2008; Shrout \& Bolger, 2002). For ease of interpretation, we mean-centered the variables used to compute the interaction terms before the analysis (Aiken \& West, 1991). Mediation exists if the $95 \%$ confidence interval (CI) of the indirect effect does not include zero.

In support of our prediction that corporate hypocrisy relates negatively to ESR through symbolic CSR attributions, the results showed that corporate hypocrisy is positively and significantly related to symbolic CSR attributions $(b=0.40, p<.01)$, and symbolic CSR attributions are negatively and significantly related to $\operatorname{ESR}(b=-0.16, p<.05)$. The total effect of corporate hypocrisy on ESR was $-0.23(p<.05)$, and the indirect effect was -0.08 , with the $95 \% \mathrm{CI}$ excluding zero $(-0.18,-0.02)$. Thus, $\mathrm{H} 1$ is supported.

Next, we analyzed the moderating role of task significance on the direct relationship between corporate hypocrisy and ESR. In model 1, we entered the control variables, in model 2 we entered the main effects of corporate hypocrisy and task significance, and in model 3 we entered the interaction term. We examined the significance of coefficients and change in Rsquare. The results in Table 4 provide support for H2. Specifically, the interaction between task significance and corporate hypocrisy was negative and significant $(b=-0.30, p<.01)$. Simple slope analyses showed that corporate hypocrisy was negatively related to ESR for respondents with high task significance $(b=-0.56, \mathrm{SE}=0.15, p<.01)$ but not for those with low task significance $(b=-0.01, \mathrm{SE}=0.15, p>.05)$. Figure 1 plots the interactions at high and low levels of the moderator (one standard deviation above and below the centered mean).

Insert Table 4 and Figure 1 here

We also predicted that task significance would moderate the indirect relationship between corporate hypocrisy and ESR (as mediated by symbolic CSR attributions). The results in 
Table 5 show a negative and significant interaction between task significance and corporate hypocrisy $(b=-0.28, p<.05)$. In addition, the results on the conditional indirect effects at low $(-1 \mathrm{SD})$ and high $(+1 \mathrm{SD})$ values of task significance indicate that the mediation coefficient of corporate hypocrisy on ESR is negative and significant when task significance is high $(b=-0.46,95 \% \mathrm{CI}=-0.76,-0.16)$, but not significant when task significance is low $(b=0.02,95 \% \mathrm{CI}=-0.29,0.32)$. Thus, $\mathrm{H} 3$ is also supported.

Insert Table 5 here

\section{Discussion}

In this study, we investigated the implications of corporate hypocrisy on employee social responsibility (ESR). Using cross-lagged data from a sample of employed professionals across a range of different industries and roles, we demonstrated that corporate hypocrisy leads to reduced ESR, through its effects on symbolic CSR attributions. Furthermore, the results revealed that this relationship was stronger for employees with higher task significance.

\subsection{Theoretical implications}

First, our study contributes to the literature by introducing a micro-level approach to the study of corporate hypocrisy and examining its implications for employee behavior. Specifically, our findings indicate that corporate hypocrisy has a detrimental impact on ESR, a vital employee outcome necessary to support and promote organizational CSR efforts (Aguinis \& Glavas, 2019; Vlachos et al., 2014). In doing so, we highlight the interlinkage between hypocrisy at the organizational level of analysis and social responsibility at the individual level of analysis, and offer theoretical explanations for why employees may regard CSR as a function of corporate hypocrisy. That is, we argue that corporate hypocrisy is a salient sensemaking factor that informs the process through which employees attribute 
motives and thus give meaning to their organization's CSR to ultimately decide whether or not to perform ESR.

In addition, our results lend support to nascent theoretical research on the "dark side" of CSR at the individual level of analysis (Maon, Vanhamme, De Roeck, Lindgreen, \& Swaen, 2019), by showing that when employees are faced with organizational word-deed misalignments, they are likely to question the merits of engaging in ESR, which ultimately will hinder CSR performance. Indeed, employees who are resentful of their organization's hypocrisy may feel betrayed by the word--deed inconsistency and, as a consequence, decide to rebel against the company through different forms of deviant behaviors (Rodrigo \& Arenas, 2008). According to research on external stakeholders' reactions to corporate hypocrisy, such behaviors may include attempts to actively discredit or undermine the organization's CSR efforts (Carlos \& Lewis, 2018; Leonidou \& Skarmeas, 2017; Lyon \& Montgomery, 2013; Skarmeas \& Leonidou, 2013). Future research might thus further examine employees' tendency to engage in retaliatory behaviors in response to corporate hypocrisy.

Second, we develop attribution theory by integrating it with the sensemaking perspective of CSR to understand how corporate hypocrisy informs the development of CSR attributions. In particular, our findings suggest that when employees interpret organizational CSR via their pre-existing judgments of corporate hypocrisy, they end up ascribing self-serving (i.e., symbolic) attributions to their organization's CSR practices, which then reduces their meaningfulness through work. Fundamentally, our research thus highlights that corporate hypocrisy leads individuals to question the sincerity of an organization's motives for CSR (see Bae \& Cameron, 2006; Marín et al., 2016), even if the CSR efforts are genuine and enacted with a sincere desire to contribute to social good. That is, CSR efforts undertaken by a hypocritical organization might be counter-productive to the positive outcomes the 
company intends to reap from its CSR practices (Palazzo \& Richter, 2005; Shim \& Yang, 2016). Therefore, our research supports existing theorizing that corporate hypocrisy may act as a heuristic that shapes the context in which individuals judge and make attributions about an organization's CSR motives.

Third, in line with Ong et al.'s (2018) work on the CSR sensitivity framework, we argue that task significance heightens employees' sensitivity to contextual cues that can potentially tarnish their organization's CSR activities (e.g., corporate hypocrisy) and consequently their own social responsibility efforts. Our empirical findings show that under conditions of high task significance, corporate hypocrisy negatively affects ESR (both directly and indirectly through symbolic CSR attributions), while the effects were negligible when task significance was low, thus supporting the key tenets of the theory. These results also directly contribute to extending knowledge on the boundary conditions that may influence ESR (e.g., De Roeck \& Farooq, 2018), and more globally highlight the notable role of task significance in informing employee reactions to organizational CSR (Gond et al., 2017). Moreover, at a more hypothetical level, our results suggest that employees who perceive their organization as hypocritical are more likely to disengage from ESR when they have greater CSR sensitivity (i.e., stemming from higher levels of task significance) and instead may dedicate themselves solely to their core job and/or engage in social responsibility outside the workplace (i.e., where they may feel their efforts are better placed). Future research that further investigates these dynamics could be instrumental in strengthening the tenets of the CSR sensitivity framework in the micro-CSR literature.

\subsection{Managerial implications}

Our research clearly shows that organizations need to be careful about how they are viewed by employees and ensure that they take the necessary precautions to avoid being perceived as holding standards that they are not fully living up to. As such, when managers 
are communicating future organizational actions to their employees, they need to ensure that they follow up on what they claim they will do and ensure that they are transparent in their policies and procedures. One way for organizations to minimize perceptions of corporate hypocrisy from arising in the first place is by avoiding touting their achievements or actions they deem positive, given the potential risk of backlash associated with the increased scrutiny that more often than not results from active communication strategies or excessive selfpromotion claims (Bansal \& Clelland, 2004; Bansal \& Roth, 2010; Carlos \& Lewis, 2018; Lyon \& Montgomery, 2013). Instead, organizations should settle for modest disclosure of their accomplishments so as to manage stakeholder perceptions (or misperceptions) of hypocrisy. According to some research findings (e.g., Carlos \& Lewis, 2018; Lyon \& Montgomery, 2013), organizations may also elect to remain silent on their achievements as a hypocrisy avoidance tactic. For example, in their study, Carlos and Lewis (2018) show that organizations that were members of the Dow Jones Sustainability Index, a prominent sustainability certification, remained strategically silent about their certification status in the face of reputational threats, to reduce the likelihood of being labeled as hypocrites by stakeholders. Conversely, another strategic means of dealing with the risk of appearing hypocritical is to fully communicate on both good and bad outcomes, with open and transparent discussions on both organizational accomplishments and shortcomings (Lyon \& Montgomery, 2013).

In addition to communication strategies, another means to prevent perceptions of corporate hypocrisy and ultimately symbolic attributions of CSR is to embed the organization's CSR agenda in its strategy, culture, and daily operations. Indeed, research argues that when CSR is not embedded, it is likely to be regarded as a public relations exercise that can lead to employee disengagement and deviance (Aguinis \& Glavas, 2019). Therefore, managers should carefully plan their CSR program so that it not only fits with the 
company mission, vision, and identity but also responds to the true needs of the stakeholders present in the wider societal context, to appear more authentic in their CSR engagement.

Finally, our research suggests that increased CSR sensitivity stemming from task significance will likely lead to greater ESR when employees perceive their organization as being authentic by fully upholding its commitments to stakeholders. Indeed, Ong et al. (2018) note the synergistic effect of CSR and task significance in causing employees to engage in positive extra-role work outcomes (i.e., organizational citizenship behaviors). As a result, organizations wanting to promote individual engagement in social responsibility should focus on harnessing task significance within the design of employees' jobs so that they feel they are able to truly make a significant impact on others both within and outside the workplace.

\subsection{Limitations and future research}

Our research has several methodological strengths. Our sample comprised employed professionals across a diverse range of occupational backgrounds, roles, and seniority levels, thus demonstrating the generalizability of our findings. Moreover, we made efforts to measure our variables at two separate time points and thus provisionally confirmed that corporate hypocrisy and symbolic CSR attributions do indeed precede our outcome, namely ESR (see Mitchell \& James, 2001). Nevertheless, repeated measurement points in time would help provide more convincing evidence to preclude reverse causality. Indeed, Mitchell and James (2001) suggest that scholars need to further investigate the timing of relationships and the point at which the predictor variables have a significant influence on outcomes of interest. This is especially so in the area of micro-level CSR, where longitudinal studies are rare, resulting in a limited narrative on the causality of relationships (Gond et al., 2017).

Also, because we collected self-reported data from professionals with a similar educational background, our study may have been subject to both CMV (Podsakoff et al., 2003) and selection biases (Winship \& Mare, 1992). This calls for future research to focus on 
obtaining data from different sources, such as other-reported ratings of the dependent variable, and from a more representative sample of the working population. We did however use a cross-lagged design, which, in addition to relying on validated and reliable scales, substantially diminishes CMV (Podsakoff et al., 2003).

Furthermore, although we drew on the ideas of Ong et al. (2018) to suggest that task significance heightens employees' CSR sensitivity, we did not objectively measure this proposed phenomenon of sensitivity. As Ong et al. (2018) note, there are no measures on CSR sensitivity given the recency of the construct, so future research should focus on developing a valid and reliable measure to deduce with certainty whether task significance leads to greater CSR sensitivity. Moreover, future research should explore additional factors that may affect CSR sensitivity and consequently employees' responses to corporate hypocrisy. For example, preliminary research indicates that managers' ethical stance can contribute to corporate hypocrisy judgments that will then undermine employees' engagement in their organization's CSR programs (De Roeck \& Farooq, 2018). Given this insight, future research could also investigate the impact of various leadership styles (e.g., authentic, transactional, destructive) on employees' CSR sensitivity and, as a result, on their attribution of and involvement in CSR. Research should also focus on the role of individual differences within micro-level CSR, given the scarcity of research here (Rupp \& Mallory, 2015). Indeed, employees' own values and interests can influence their propensity to engage in social responsibility both within and outside the workplace (e.g., Hejjas et al., 2019; Paillé, Raineri, \& Boiral, 2019; Rodrigo \& Arenas, 2008), and so it is reasonable to assume that their CSR-related values and beliefs would also affect felt CSR sensitivity.

Moreover, research tends to examine perceptions of corporate hypocrisy rather than assessing it from an objective standpoint (e.g., Arli et al., 2017; Marín et al., 2016; Scheidler et al., 2019; Wagner et al., 2009). Judgments of hypocrisy signify that employees perceive a 
misalignment between the organization's claimed standards and its actual behavior, while objective evidence of such inconsistency might not exist. That is, it could be argued that perceptions of corporate hypocrisy may be inaccurate and/or misinformed, leading employees to view their organization as hypocritical when in fact it is not. Indeed, empirical evidence shows that organizations are cognizant of the potential for their actions to be misperceived as hypocritical, as highlighted by Carlos and Lewis's (2018) study, which demonstrates that organizations may strategically elect to withhold a prominent certification status obtained from an independent verification agency as a hypocrisy-avoidance tactic. As such, a worthwhile avenue for research would be to further investigate communication strategies and campaigns, beyond strategic silence, that could help an organization minimize (mis)perception of corporate hypocrisy.

Finally, greater clarity is required on ESR as a construct. Rupp and Mallory (2015) note that micro-level CSR suffers from the dilemma of specificity, with the little research there is on ESR being similarly fragmented. Prior research on ESR has adopted a narrow focus in for instance looking at environmental behaviors or volunteering behaviors, while others have taken a more multi-dimensional focus (e.g., De Roeck \& Farooq, 2018; Paillé et al., 2019; Rodell, 2013). In our study, in line with Vlachos et al. (2014), we conceptualized ESR as socially responsible behaviors that capture discretionary support for and involvement in organizational CSR initiatives. To foster common agreement, future research on ESR should focus on the development of a valid and reliable multi-dimensional measure of ESR to drive more consistent and robust research efforts on the nomological network of ESR, including the outcomes of ESR itself. Undeniably, the fundamental objective of social responsibility is to further social good, so the question yet to be answered is: will propagating ESR in the workplace lead to an improvement in overall societal conditions? 


\section{References}

Aguinis, H., \& Glavas, A. (2019). On corporate social responsibility, sensemaking, and the search for meaningfulness through work. Journal of Management, 45, 1057-1086.

Aiken, L. S., \& West, G. (1991). Multiple regression: Testing and interpreting interactions. Thousand Oaks, CA: Sage.

Allan, B. A. (2017). Task significance and meaningful work: A longitudinal study. Journal of Vocational Behavior, 102, 174-182.

Arli, D., Grace, A., Palmer, J., \& Pham, C. (2017). Investigating the direct and indirect effects of corporate hypocrisy and perceived corporate reputation on consumers' attitudes toward the company. Journal of Retailing and Consumer Services, 37, 139145.

Bae, J., \& Cameron, G. T. (2006). Conditioning effect of prior reputation on perception of corporate giving. Public Relations Review, 32, 144-150.

Bansal, P., \& Clelland, I. (2004). Talking trash: Legitimacy, impression management, and unsystematic risk in the context of the natural environment. Academy of Management Journal, 47, 93-103.

Bansal, P., \& Roth, K. (2000). Why companies go green: A model of ecological responsiveness. Academy of Management Journal, 43, 717-736.

Becker, T. E., Atinc, G., Breaugh, J. A., Carlson, K. D., Edwards, J. R., \& Spector, P. E. (2016). Statistical control in correlational studies: 10 essential recommendations for organizational researchers. Journal of Organizational Behavior, 37, 157-167.

Bentler, P. M., \& Bonett, D. G. (1980). Significance tests and goodness of fit in the analysis of covariance structures. Psychological Bulletin, 88, 588-606. 
Cadwalladr, C. (2012). The hypocrisy of Burberry's "Made in Britain” appeal (16-07-12). The Guardian. https://www.theguardian.com/commentisfree/2012/jul/16/burberrychina-british-carole-cadwalladr. Accessed 15 May 2019.

Carlos, W. C., \& Lewis, B. W. (2018). Strategic silence: Withholding certification status as a hypocrisy avoidance tactic. Administrative Science Quarterly, 63, 130-169.

Chen, Y.-S., \& Chang, C.-H. (2013). Greenwash and green trust: The mediation effects of green consumer confusion and green perceived risk. Journal of Business Ethics, 114, 489-500.

Cheung, G. W., \& Lau, R. S. (2008). Testing mediation and suppression effects of latent variables: Bootstrapping with structural equation models. Organizational Research Methods, 11, 296-325.

Christensen, L. T., Morsing, M., \& Thyssen, O. (2013). CSR as aspirational talk. Organization, 20, 372-393.

De Roeck, K., \& Farooq, O. (2018). Corporate social responsibility and ethical leadership: Investigating their interactive effect on employees' socially responsible behaviors. Journal of Business Ethics, 151, 923-939.

De Roeck, K., \& Maon, F. (2018). Building the theoretical puzzle of employees' reactions to corporate social responsibility: An integrative conceptual framework and research agenda. Journal of Business Ethics, 149, 609-625.

Donia, M. B. L., Ronen, S., Tetrault Sirsly, C. A. T., \& Bonaccio, S. (2017a). CSR by any other name? The differential impact of substantive and symbolic CSR attributions on employee outcomes. Journal of Business Ethics, 157, 503-523.. 
Donia, M. B. L., Tetrault Sirsly, C.-A., \& Ronen, S. (2017b). Employee attributions of corporate social responsibility as substantive or symbolic: Validation of a measure. Applied Psychology, 66, 103-142.

Du, S., Bhattacharya, C. B., \& Sen, S. (2010). Maximizing business returns to corporate social responsibility (CSR): The role of CSR communication. International Journal of Management Reviews, 12, 8-19.

Fassin, Y., \& Buelens, M. (2011). The hypocrisy-sincerity continuum in corporate communication and decision making: A model of corporate social responsibility and business ethics practices. Management Decision, 49, 586-600.

Fornell, C., \& Larcker, D. F. (1981). Evaluating structural equations models with unobservable variables and measurement error. Journal of Marketing Research, 18, 39-50.

Godfrey, P. C. (2005). The relationship between corporate philanthropy and shareholder wealth: A risk management perspective. Academy of Management Review, 30, 777798.

Gond, J. P., El Akremi, A., Swaen, V., \& Babu, N. (2017). The psychological microfoundations of corporate social responsibility: A person-centric systematic review. Journal of Organizational Behavior, 38, 225-246.

Goštautaitè, B., \& Bučiūnienè, I. (2015). Work engagement during life-span: The role of interaction outside the organization and task significance. Journal of Vocational Behavior, 89, 109-119.

Grant, A. M. (2008). The significance of task significance: Job performance effects, relational mechanisms, and boundary conditions. Journal of Applied Psychology, 93, 108-124. 
Greenbaum, R. L., Mawritz, M. B., \& Piccolo, R. F. (2015). When leaders fail to "walk the talk" supervisor undermining and perceptions of leader hypocrisy. Journal of Management, 41, 929-956.

Hackman, J. R., \& Oldham, G. R. (1975). Development of the job diagnostic survey. Journal of Applied Psychology, 60, 159-170.

Hair, Jr., J. F., Black, W. C., Babin, B. J., \& Anderson, R. E. (2010). Multivariate data analysis: A global perspective (7th ed.). Upper Saddle River, NJ: Prentice Hall.

Hayes, A. F. (2013). Introduction to mediation, moderation, and conditional process analysis. New York: Guilford Press.

Hejjas, K., Miller, G., \& Scarles, C. (2019). “It's like hating puppies”! Employee disengagement and corporate social responsibility. Journal of Business Ethics, 157, 319-337.

Hu, L. T., \& Bentler, P. M. (1999). Cutoff criteria for fit indexes in covariance structure analysis: Conventional criteria versus new alternatives. Structural Equation Modeling: A Multidisciplinary Journal, 6, 1-55.

Janney, J. J., \& Gove, S. (2011). Reputation and corporate social responsibility aberrations, trends, and hypocrisy: Reactions to firm choices in the stock option backdating scandal. Journal of Management Studies, 48, 1562-1585.

Kelley, H. H., \& Michela, J. L. (1980). Attribution theory and research. Annual Review of Psychology, 31, 457-501.

Lange, D., \& Washburn, N. T. (2012). Understanding attributions of corporate social irresponsibility. Academy of Management Review, 37, 300-326. 
Leonidou, C. N., \& Skarmeas, D. (2017). Gray shades of green: Causes and consequences of green skepticism. Journal of Business Ethics, 144, 401-415.

Lyon, T. P., \& Montgomery, A. W. (2013). Tweetjacked: The impact of social media on corporate greenwash. Journal of Business Ethics, 118, 747-757.

Maon, F., Vanhamme, J., De Roeck, K., Lindgreen, A., \& Swaen, V. (2019). The dark side of stakeholder reactions to corporate social responsibility: Tensions and micro-level undesirable outcomes. International Journal of Management Reviews, 21, 209-230.

Marín, L., Cuestas, P. J., \& Román, S. (2016). Determinants of consumer attributions of corporate social responsibility. Journal of Business Ethics, 138, 247-260.

Mazutis, D. D., \& Slawinski, N. (2015). Reconnecting business and society: Perceptions of authenticity in corporate social responsibility. Journal of Business Ethics, 131, 137150.

McWilliams, A., Siegel, D. S., \& Wright, P. M. (2006). Corporate social responsibility: Strategic implications. Journal of Management Studies, 43, 1-18.

Mitchell, T. R., \& James, L. R. (2001). Building better theory: Time and the specification of when things happen. Academy of Management Review, 26, 530-547.

Morgeson, F. P., \& Humphrey, S. E. (2006). The Work Design Questionnaire (WDQ): Developing and validating a comprehensive measure for assessing job design and the nature of work. Journal of Applied Psychology, 91, 1321-1339.

Muthén, L. K., \& Muthén, B. O. (2013). Mplus user's guide. Los Angeles, CA: Muthen \& Muthen.

Newman, D. A. (2014). Missing data: Five practical guidelines. Organizational Research Methods, 17, 372-411. 
Ong, M., Mayer, D. M., Tost, L. P., \& Wellman, N. (2018). When corporate social responsibility motivates employee citizenship behavior: The sensitizing role of task significance. Organizational Behavior and Human Decision Processes, 144, 44-59.

Organ, D. W. (1988). Organizational citizenship behavior: The good soldier syndrome. Lexington, MA: Lexington Books.

Paillé, P., Morelos, J. H. M., Raineri, N., \& Stinglhamber, F. (2019). The influence of the immediate manager on the avoidance of non-green behaviors in the workplace: A three-wave moderated-mediation model. Journal of Business Ethics, 155, 723-740.

Paillé, P., Raineri, N., \& Boiral, O. (2019). Environmental behavior on and off the job: A configurational approach. Journal of Business Ethics, 158, 253-268.

Palazzo, G., \& Richter, U. (2005). CSR business as usual? The case of the tobacco industry. Journal of Business Ethics, 61, 387-401.

Podsakoff, P. M., MacKenzie, S. B., Lee, J. Y., \& Podsakoff, N. P. (2003). Common method biases in behavioral research: A critical review of the literature and recommended remedies. Journal of Applied Psychology, 88, 879-903.

Preacher, K. J., \& Hayes, A. F. (2008). Asymptotic and resampling strategies for assessing and comparing indirect effects in multiple mediator models. Behavior Research Methods, 40, 879-891.

Ramus, C. A., \& Montiel, I. (2005). When are corporate environmental policies a form of greenwashing? Business \& Society, 44, 377-414.

Rodell, J. B. (2013). Finding meaning through volunteering: Why do employees volunteer and what does it mean for their jobs? Academy of Management Journal, 56, 12741294. 
Rodrigo, P., \& Arenas, D. (2008). Do employees care about CSR programs? A typology of employees according to their attitudes. Journal of Business Ethics, 83, 265-283.

Rupp, D. E., \& Mallory, D. B. (2015). Corporate social responsibility: Psychological, personcentric, and progressing. Annual Review of Organizational Psychology and Organizational Behavior, 2, 211-236.

Scheidler, S., Edinger-Schons, L. M., Spanjol, J., \& Wieseke, J. (2019). Scrooge posing as Mother Teresa: How hypocritical social responsibility strategies hurt employees and firms. Journal of Business Ethics, 157, 339-358.

Shim K., \& Yang, S-U. (2016). The effect of bad reputation: The occurrence of crisis, corporate social responsibility, and perceptions of hypocrisy and attitudes toward a company. Public Relations Review, 42, 68-78.

Shrout, P. E., \& Bolger, N. (2002). Mediation in experimental and nonexperimental studies: New procedures and recommendations. Psychological Methods, 7, 422-445.

Skarmeas, D., \& Leonidou, C. N. (2013). When consumers doubt, Watch out! The role of CSR skepticism. Journal of Business Research, 66, 1831-1838.

Vlachos, P. A., Panagopoulos, N. G., Bachrach, D. G., \& Morgeson, F. P. (2017). The effects of managerial and employee attributions for corporate social responsibility initiatives. Journal of Organizational Behavior, 38, 1111-1129.

Vlachos, P. A., Panagopoulos, N. G., \& Rapp, A. (2014). Employee judgments of and behaviors towards corporate social responsibility: A multi-study investigation of direct, cascading, and moderating effects, Journal of Organizational Behavior, 35, 990-1017. 
Vlachos, P. A., Theotokis, A., \& Panagopoulos, N. G. (2010). Sales force reactions to corporate social responsibility: Attributions, outcomes, and the mediating role of organizational trust. Industrial Marketing Management, 39, 1207-1218.

Wagner, T., Lutz, R. J., \& Weitz, B. A. (2009). Corporate hypocrisy: Overcoming the threat of inconsistent corporate social responsibility perceptions. Journal of Marketing, 73, $77-91$

Weick, K. E. (1995). Sensemaking in organizations. Thousand Oaks, CA: Sage.

Winship, C., \& Mare, R. D. (1992). Models for sample selection bias. Annual Review of Sociology, 18, 327-350.

Zavyalova, A., Pfarrer, M. D., Reger, R. K., \& Shapiro, D. L. (2012). Managing the message: The effects of firm actions and industry spillovers on media coverage following wrongdoing. Academy of Management Journal, 55, 1079-1101. 


\section{Table 1}

Summary of sample characteristics by percentage $(N=155)$

\section{Gender}

Female

Age

$<30$ years

30-39 years

40-49 years 20.0

50-59 years

$>60$ years

Organizational tenure

$<1$ year

1-5 years 51.0

6-10 years 25.2

11-20 years

$>20$ years

Job level

Senior management

Middle management 28.4

First-line management 29.7 
Table 2

Confirmatory factor analysis

\begin{tabular}{|c|c|c|c|c|c|c|}
\hline Model & $\chi^{2}$ & df & $\Delta \chi^{2}$ & CFI & TLI & RMSEA \\
\hline One-factor (all items combined) & 819.44 & 103 & $667.72^{\mathrm{a}}$ & .51 & .42 & .21 \\
\hline Two-factor (corporate hypocrisy and symbolic CSR attributions combined, & 617.72 & 102 & $466.00^{\mathrm{a}}$ & .64 & .58 & .18 \\
\hline \multicolumn{7}{|l|}{ task significance, and ESR combined) } \\
\hline Three-factor 1 (corporate hypocrisy and symbolic CSR attributions combined) & 386.12 & 100 & $234.40^{\mathrm{a}}$ & .80 & .76 & .14 \\
\hline Three-factor 2 (task significance and ESR combined) & 386.78 & 100 & $235.06^{\mathrm{a}}$ & .80 & .76 & .14 \\
\hline Four-factor (hypothesized model) & 151.72 & 97 & & .96 & .95 & .06 \\
\hline
\end{tabular}

${ }^{a}$ Chi-square change significant at $p<.001$.

Notes CFI = Comparative Fit Index; TLI = Tucker-Lewis Index; RMSEA = Root Mean Square Error of Approximation. 


\section{Table 3}

Summary statistics and zero-order correlations

\begin{tabular}{|c|c|c|c|c|c|c|c|c|c|c|c|c|c|c|}
\hline Variable & Mean & SD & $\alpha$ & $\rho$ & AVE & 1 & 2 & 3 & 4 & 5 & 6 & 7 & 8 & 9 \\
\hline 1. Gender $($ female $=1$, male $=2)$ & 1.42 & 0.49 & - & - & - & - & & & & & & & & \\
\hline 2. Age ${ }^{a}$ & 1.87 & 0.74 & - & - & - & .19 & - & & & & & & & \\
\hline 3. Organizational tenure ${ }^{b}$ & 2.40 & 0.92 & - & - & - & .05 & .46 & - & & & & & & \\
\hline 4. Job level ${ }^{\mathrm{c}}$ & 2.43 & 1.05 & - & - & - & .13 & .38 & .30 & - & & & & & \\
\hline 5. Job satisfaction (time 1) & 5.22 & 1.48 & - & - & - & .05 & .14 & .09 & .21 & - & & & & \\
\hline 6. Corporate hypocrisy (time 1) & 1.98 & 0.78 & .93 & .91 & .64 & -.03 & -.18 & -.08 & -.26 & -.43 & $(.80)$ & & & \\
\hline 7. Symbolic CSR attributions (time 1) & 2.88 & 1.13 & .86 & .87 & .64 & .11 & -.17 & -.14 & -.19 & -.22 & .33 & $(.80)$ & & \\
\hline 8. Task significance (time 1 ) & 2.78 & 0.92 & .86 & .88 & .70 & .05 & .05 & .07 & .22 & .42 & -.26 & -.15 & $(.84)$ & \\
\hline 9. ESR (time 2) & 3.29 & 1.03 & .85 & .87 & .69 & .01 & .10 & .06 & .15 & .17 & -.32 & -.27 & .24 & $(.83)$ \\
\hline
\end{tabular}

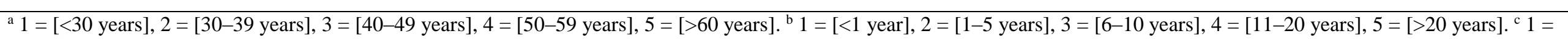
non-management, 2 = first-line management, 3 = middle management, 4 = senior management .

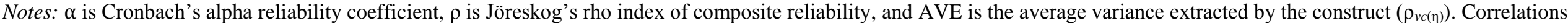
greater than $|.20|$ are significant at $p<.01$; those greater than $|.16|$ are significant at $p<.05$. Diagonal elements (in parentheses) are the square roots of the AVE. 


\section{Table 4}

Regression results on ESR

\begin{tabular}{|c|c|c|c|c|c|c|}
\hline \multirow[t]{2}{*}{ Regression model } & \multicolumn{2}{|l|}{ Model 1} & \multicolumn{2}{|l|}{ Model 2} & \multicolumn{2}{|l|}{ Model 3} \\
\hline & $b(S E)$ & $95 \% \mathrm{CI}$ & $b(S E)$ & $95 \% \mathrm{CI}$ & $b(S E)$ & $95 \% \mathrm{CI}$ \\
\hline (Constant) & $2.42(0.36)^{* * *}$ & {$[1.70,3.13]$} & $3.22(0.55)^{* * *}$ & {$[2.13,4.30]$} & $3.09(0.40)^{* * *}$ & {$[2.29,3.88]$} \\
\hline Age & $0.12(0.12)$ & {$[-0.12,0.35]$} & $0.11(0.12)$ & {$[-0.12,0.35]$} & $0.05(0.12)$ & {$[-0.18,0.28]$} \\
\hline Job level & $0.08(0.09)$ & {$[-0.09,0.25]$} & $0.03(0.09)$ & {$[-0.14,0.20]$} & $0.03(0.08)$ & {$[-0.14,0.20]$} \\
\hline Job satisfaction & $0.09(0.06)$ & {$[-0.02,0.20]$} & $-0.01(0.06)$ & {$[-0.14,0.11]$} & $-0.00(0.06)$ & {$[-0.13,0.12]$} \\
\hline Corporate hypocrisy & & & $-0.30(0.11)^{* *}$ & {$[-0.52,-0.07]$} & $-0.28(0.09)^{*}$ & {$[-0.51,-0.06]$} \\
\hline Task significance & & & $0.16(0.10)$ & {$[-0.03,0.36]$} & $0.21(0.09)^{*}$ & {$[0.02,0.40]$} \\
\hline Corporate hypocrisy $\times$ task significance & & & & & $-0.30(0.12)^{* *}$ & {$[-0.51,-0.08]$} \\
\hline$R^{2}$ & .04 & & .10 & & .14 & \\
\hline$\Delta R^{2}$ & - & & $.06 * *$ & & $.04 * *$ & \\
\hline
\end{tabular}




\section{Table 5}

Regression results for moderated-mediation model

\begin{tabular}{|c|c|c|c|c|}
\hline \multirow[t]{2}{*}{ Regression model } & \multicolumn{2}{|c|}{ Symbolic CSR Attributions } & \multicolumn{2}{|l|}{ ESR } \\
\hline & $b(S E)$ & $95 \% \mathrm{CI}$ & $b(S E)$ & $95 \% \mathrm{CI}$ \\
\hline (Constant) & $3.57(0.42)^{* * *}$ & {$[2.75,4.40]$} & $3.65(0.47)^{* * *}$ & {$[2.71,4.59]$} \\
\hline Age & $-0.11(0.12)$ & {$[-0.36,0.13]$} & $0.04(0.12)$ & {$[-0.19,0.27]$} \\
\hline Job level & $-0.10(0.09)$ & {$[-0.28,0.08]$} & $0.02(0.08)$ & {$[-0.15,0.18]$} \\
\hline Job satisfaction & $-0.05(0.06)$ & {$[-0.17,0.08]$} & $-0.01(0.06)$ & {$[-0.13,0.11]$} \\
\hline Corporate hypocrisy & $0.40(0.12)^{* *}$ & {$[0.16,0.64]$} & $-0.22(0.11)$ & {$[-0.45,0.01]$} \\
\hline Task significance & & & $0.19(0.10)^{*}$ & {$[0.00,0.38]$} \\
\hline Symbolic CSR attributions & & & $-0.16(0.07)^{*}$ & {$[-0.31,-0.01]$} \\
\hline Corporate hypocrisy $\times$ task significance & & & $-0.28(0.11)^{*}$ & {$[-0.48,-0.04]$} \\
\hline$R^{2}$ & .13 & & .17 & \\
\hline$F$ & $5.81 * * *$ & & $4.32 * * *$ & \\
\hline \multirow[t]{2}{*}{ Conditional indirect effect ${ }^{\mathrm{a}}$} & \multicolumn{2}{|c|}{ Low (-1 SD) Task Significance } & $0.02(0.15)$ & {$[-0.29,0.32]$} \\
\hline & \multicolumn{2}{|c|}{ High (+1 SD) Task Significance } & $-0.46(0.15)^{* *}$ & {$[-0.76,-0.16]$} \\
\hline
\end{tabular}

a 5,000 bootstrap resampling.

$* p<.05 . * * p<.01 . * * * p<.001$. 
Fig. 1. Interaction effect of corporate hypocrisy and task significance on ESR.

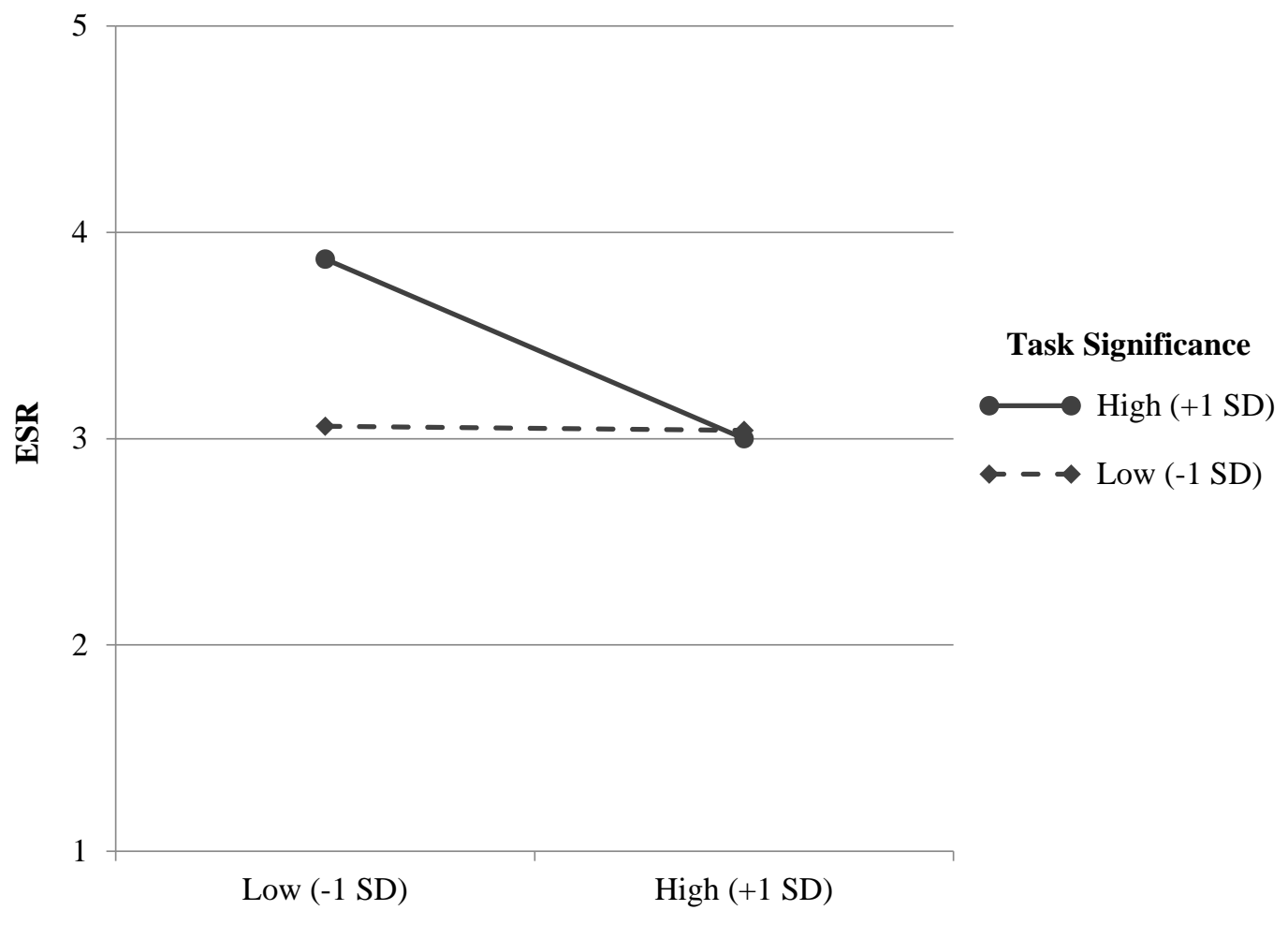

Corporate Hypocrisy 


\section{Appendix.}

\section{Construct validity}

Scales

Standardized $\rho$

AVE

Loadings

Corporate Hypocrisy

$.91 \quad .64$

My organization keeps its promises. (R) .78

My organization acts hypocritically.

My organization pretends to be something that it is not.

My organization puts its words into action. (R)

My organization does exactly what it says. (R)

What my organization says and does are two different things.

My organization engages in CSR to avoid looking bad in front of the public.

My organization engages in CSR to appear to be an ethical organization.

My organization engages in CSR to look better than its competitors.

My organization engages in CSR to avoid criticism from the media and/or external

stakeholders (suppliers, customers, the community).

Task Significance

The results of my work are likely to significantly affect the lives of other people.

The job has a large impact on people outside the organization.

The work performed on the job has a significant impact outside the organization.

I contributed many ideas for improving my organization's CSR initiatives.

I got actively involved in the implementation of my organization's CSR initiatives.

I publicly showed support for my organization's CSR initiatives.

(R) indicates item is reverse scored. 